\title{
IbM Pembentukan Posyandu Lansia
}

\author{
Mekar Dwi Anggraeni ${ }^{1 *}$, Amin Fatoni ${ }^{2}$, Warsinah ${ }^{3}$ \\ ${ }^{1}$ Jurusan Keperawatan, Fakutas Ilmu-ilmu Kesehatan, Universitas Jenderal Soedirman, Purwokerto, \\ Indonesia \\ 2Jurusan Kimia, Fakutas MIPA, Universitas Jenderal Soedirman, Purwokerto, Indonesia \\ ${ }^{3}$ Jurusan Farmasi, Fakutas Ilmu-ilmu Kesehatan, Universitas Jenderal Soedirman, Purwokerto, Indonesia \\ *Penulis korespondensi, email: mekar.dwi@gmail.com
}

\section{Submit :}

1 Des 2019

Diterima:

10 Des 2019

Terbit:

20 Des 2019

\begin{abstract}
Abstrak. Pengabdian Kepada Masyarakat (PKM) yang telah dilakukan berupa pembentukan dan pelaksanaan Posyandu Lansia di RT 1 dan 3 RW 1 dan RW 4 Kelurahan Bancar Kembar Kecamatan Purwokerto Utara Kabupaten Banyumas. Pelaksanaan pengabdian selama 8 bulan yaitu bulan April sampai dengan November 2017. Tujuan dilaksanakannya PKM ini adalah pemberdayaan masyarakat terkait dengan Posyandu Lansia meliputi: Pembentukan Posyandu Lansia, Pelatihan Kader Posyandu, Pelatihan Senam Lansia, Pelatihan cek kadar glukosa, kolesterol, asam urat darah, siraman rohani, serta Pelatihan cara mengukur tekanan darah. Hasil dari kegiatan PKM menunjukkan anggota masyarakat sangat bersemangat dengan adanya pembentukan dan pelaksanaan Posyandu Lansia. Hal ini disebabkan karena kader Posyandu Lansia mendapatkan berbagai pelatihan dan peralatan yang menunjang pelaksanaan Posyandu lansia. Para lansia juga bersemangat mengikuti berbagai aktivitas pada saat Posyandu Lansia yaitu senam lansia, penimbangan berat badan, pengukuran berat badan, pengukuran tekanan darah, deteksi dini kadar kolesterol, asam urat dan gula darah, siraman rohani, pendidikan kesehatan tentang pola hidup sehat, pemberian makanan tambahan, dan manajemen penyakit kronis. Posyandu lansia merupakan salah satu wadah bagi upaya pencegahan penyakit dan promosi kesehatan bagi lansia sehingga dapat menekan biaya pengobatan penyakit yang dikeluarkan oleh masyarakat dan negara.
\end{abstract}

Kata Kunci: pemberdayaan masyarakat, posyandu lansia, lansia 


\section{Pendahuluan}

Kelurahan Bancarkembar Kecamatan Purwokerto Utara Kabupaten Banyumas mempunyai 10 RW. Pada RW 1 terdiri dari 3 RT yaitu RT 1, RT 2, dan RT 3. Kegiatan posyandu balita warga RT 1 dan RT 3 RW 1 bergabung dengan nama posyandu Belimbing. Posyandu ini dilaksanakan di RT 3 RW 1 dengan para kader juga berasal dari RT 3 RW 1. RW 4 Kelurahan Bancarkembar Kecamatan Purwokerto Utara Kabupaten Banyumas mempunyai 3 RT yaitu RT 1, RT 2, dan RT 3. RW 4 juga sudah mempunyai posyandu balita dengan nama posyandu balita Cempedak. Permasalahan utama yang terjadi pada kedua mitra adalah tidak adanya layanan posyandu lansia. Hal ini disebabkan karena belum adanya pembinaan dan pelayanan fasilitas untuk terlaksananya kegiatan tersebut. Dengan adanya pembinaan dan pelayanan kesehatan lansia ini maka dapat menjadi cikal bakal berdirinya posyandu lansia. Pelayanan posyandu lansia sangat diperlukan sebagai wadah meningkatkan kesehatan jasmani dan rohani. Pemeriksaan kesehatan dapat dilakukan secara rutin sehingga menurunkan angka pasien yang dirawat di rumah sakit.

Penduduk pada RW 1 dan RW4 Kelurahan Bancarkembar Kecamatan Purwokerto Utara Kabupaten Banyumas banyak yang sudah memasuki lanjut usia. Jumlah warga pada RW 1 adalah 370 jiwa dengan jumlah lansia sebanyak 83 jiwa. Jumlah warga pada RW 4 adalah 390 jiwa dengan jumlah lansia sebanyak 98 jiwa. Mata pencarian warga pada kedua tempat tersebut adalah buruh, tukang becak, tukang bangunan, pembantu rumah tangga dan hanya sedikit warga yang mempunyai pendapatan di atas Upah Minimal Kabupaten (UMK). UMK Kabupaten Banyumas semenjak 1 April 2016 adalah sebesar Rp 1.350 .000 (Pemerintah Kabupaten Banyumas, 2016). Lansia yang ada di kedua RW berada pada kondisi ekonomi menengah bawah dan hanya sedikit yang berkecukupan.

Masyarakat banyak yang beranggapan bahwa kehidupan masa tua tidak lagi memberikan banyak manfaat, bahkan ada yang sampai beranggapan bahwa kehidupan masa tua, seringkali dipersepsikan secara negatif sebagai beban keluarga dan masyarakat karena kondisi kesehatan fisik yang berkurang dan cenderung sering sakit. Untuk mengatasi hal ini perlu adanya upaya promotif yaitu untuk menggairahkan semangat hidup bagi lansia agar mereka tetap dihargai dan berguna bagi dirinya sendiri. Disamping itu perlu adanya upaya preventif yaitu upaya pencegahan terhadap kemungkinan terjadinya penyakit maupun komplikasi penyakit yang disebabkan oleh proses ketuaan. Upaya-upaya tersebut dapat dilakukan dengan pelayanan kesehatan lansia yang berbasiskan keluarga, masyarakat dan lembaga. Dalam pelayanan lansia tenaga kesehatan dapat dibantu oleh kader. Kader adalah seorang tenaga sukarela yang direkrut dari, oleh dan untuk masyarakat, yang bertugas membantu kelancaran pelayanan kesehatan. Kader yang sudah baik dapat memberikan dukungan positif dan memberikan pendidikan pada lansia untuk melakukan pemeriksaan kesehatan secara rutin (Setyoadi, dkk., 2013).

Berdasarkan wawancara dengan kader posyandu balita di wilayah RW 1 dan RW 4 Kelurahan Bancarkembar Kecamatan Purwokerto Utara Kabupaten Banyumas warga hanya memiliki posyandu balita dan belum memiliki wadah yang melayani kesehatan lansia. Hal ini akan berdampak negatif terhadap derajat kesehatan lansia. Warga sangat berharap masyarakat diberdayakan untuk memberikan layanan kesehatan para lansia.

Proses penuaan akan berdampak pada berbagai aspek kehidupan baik 
sosial, ekonomi dan kesehatan. Ditinjau dari aspek kesehatan dengan semakin bertambahnya usia, maka lansia lebih rentan terhadap berbagai keluhan fisik, baik karena faktor alamiah maupun karena penyakit. Penyakit yang banyak diderita oleh lansia adalah hipertensi, artritis, stroke, penyakit paru, dan diabetes mellitus (Kementeriaan Kesehatan RI, 2014). Lansia yang mengalami kesulitan dalam melakukan aktivitas sehari-hari akan berdampak pada kualitas hidupnya, terlebih lansia yang sedang mengalami sakit, sehingga diperlukan bantuan orang lain agar kualitas hidupnya tidak semakin menurun (Bowling, 2007).

Camacho dkk (2009) menyatakan kebijakan pelayanan kesehatan berpengaruh terhadap peningkatan status kesehatan lansia melalui upaya perawatan kesehatan primer secara profesional. Pemerintah telah merumuskan berbagai kebijakan pelayanan kesehatan usia lanjut yang ditujukan untuk meningkatkan derajat kesehatan dan mutu kehidupan lansia untuk mencapai masa tua yang bahagia dan berdaya guna dalam kehidupan keluarga dan masyarakat sesuai dengan keberadaanya. Pemerintah telah mencanangkan pelayanan pada lansia melalui perubahan jenjang pelayanan kesehatan. Pelayanan di tingkat masyarakat adalah posyandu lansia.

Keuntungan yang diperoleh oleh para lansia di RT 01 dan 03 dan RW 04 adalah peningkatan kualitas hidup lansia melalui penyelenggaraan posyandu lansia. Dengan adanya posyandu dapat memberi manfaat bagi lansia. Manfaatnya dapat ditinjau dari aspek fisik dan aspek psikis. Manfaat secara aspek fisik yaitu kondisi kesehatan senantiasa terjaga atau sehat. Manfaat secara aspek psikis yang dirasakan yaitu perasaan senang dapat bertemu sesama lansia. Keaktifan lansia dalam mengikuti kegiatan posyandu dipengaruhi oleh dukungan dari keluarga (Pertiwi,
2013), jenis kelamin (Sudaryanto, 2008), pendapatan, dan jenis pekerjaan (Rosyid, 2007), serta pengetahuan (Dodo, 2008).

\section{METODE}

Pelaksanaan kegiatan pengabdian kepada masyarakat diselenggarakan pada warga masyarakat di RT 1, RT 2 pada RW 1 dan RT 3 pada RW 4 Kelurahan Bancarkembar Kecamatan Purwokerto Utara Kabupaten Banyumas. Pemilihan khalayak sasaran tersebut didasarkan atas pertimbangan jumlah lansia di wilayah tersebut banyak, kepentingan dan tujuan pembentukan Posyandu Lansia serta tingginya tingkat partisipasi dan kerjasama dari kader kesehatan dan para lansia untuk mengadopsi tekhnologi yang dialihkan. Para calon kader Posyandu lansia merupakan kader Posyandu balita sehingga sudah memiliki pengalaman mengelola Posyandu hanya berbeda sasaran pelaksanaan Posyandu.

Metode alih tekhnologi yang digunakan untuk merealisasikan program IbM ini adalah melalui penyuluhan, diskusi, pelatihan, demonstrasi, dan pendampingan. Kegiatan pertama yang dilakukan adalah pembentukan Posyandu Lansia, penentuan susunan pengurus Posyandu Lansia, dan alih tekhnologi tentang manajemen pengelolaan Posyandu Lansia. Kegiatan kedua adalah pelatihan cara mengukur berat badan, tinggi badan, dan tekanan darah bagi kader, pelaksanaan Posyandu Lansia pertama, senam lansia, dan pendidikan kesehatan tentang pola hidup sehat. Kegiatan ketiga adalah pelaksanaan Posyandu Lansia kedua dan siraman rohani karena bertepatan dengan bulan Ramadhan. Kegiatan keempat adalah pelatihan cara mengukur kadar kolesterol, kadar asam urat dan kadar gula darah, senam lansia, pelaksanaan posyandu lansia ketiga, dan pendidikan kesehatan tentang manajemen hiperkolesterol pada lansia. Pengabdi melakukan 
pendampingan pelaksanaan Posyandu Lansia selama empat bulan selanjutnya. Pendampingan ini bertujuan untuk memonitor dan mendiskusikan masalah yang muncul selama pelaksanaan Posyandu Lansia agar kegiatan Posyandu Lansia dapat berjalan dengan lancar. Pengabdi juga berkoordinasi dengan tenaga kesehatan dari Puskesmas Purwokerto Utara 1 untuk menjamin keberlanjutan program Posyandu Lansia karena hal tersebut merupakan bagian dari program kerja Puskesmas.

\section{HASIL DAN PEMBAHASAN}

Hasil dari kegiatan pengabdian ini dapat dilihat dari terbentuknya Posyandu lansia, terdapatnya pengurus Posyandu lansia, terlaksananya Posyandu lansia sebanyak 4 kali (satu kali perbulan), dan senam lansia yang diadakan 2 kali perminggu. Hasil pengabdian diuraikan perkegiatan sebagai berikut.

\section{Pembentukan Kader dan Sosialisasi Manajemen Posyandu Lansia}

Pembentukan kader dilakukan dengan mengundang perwakilan calon kader yang berasal dari masyarakat Desa Bancarkembar. Jumlah kader yang mengikuti acara pembentukan kader dan sosialisasi manajemen posyandu lansia berjumlah 15 orang dengan perincian sebagai berikut : 5 dari RT 1 dan RT 3 RW 1 dan 10 orang dari RT 1, RT 2, dan RT 3 RW 4. Para calon kader berkumpul di rumah salah satu warga dan selanjutnya dilakukan pembentukan posyandu lansia. Kegiatan sosialisasi manajemen Posyandu Lansia diawali dengan pretest sebagai dasar pengetahuan khalayak sasaran terhadap materi yang akan diberikan. Pengabdi memberikan materi tentang Posyandu Lansia, definisi, tujuan, manfaat, sistem 5 meja, menyusun program kegiatan Posyandu Lansia yang terdiri atas pemberian makanan tambahan sehat, pola hidup sehat, senam, siraman rohani. Setiap kader mendapatkan 1 booklet "menuju lansia sehat dan bahagia". Tim pengabdi juga melakukan penyerahan alat pengukur tinggi badan dan berat badan, meja dan seperangkat alat speaker kepada kader ponsyandu lansia RW 1 dan RW 4. Kegiatan pertama diakhiri dengan post-test untuk mengetahui peningkatan pengetahuan dari khalayak sasaran setelah dilaksanakan alih tekhnologi. Hasil pre-test dan post-test dapat dilihat pada Gambar 1 dan Gambar 2.

Data pada Gambar 1 menunjukkan bahwa pada tes awal para kader RT 1 dan 3 RW 1 sudah menjawab dengan benar pertanyaan nomor $1,2,4,9$ dan 10. Para kader masih banyak menjawab salah pada pertanyaan nomor 3, 5, 6, 7, dan 8. Median skor pretest adalah 3 (Min-Maks $=0-10$ ). Pada tes akhir para kader sudah bisa menjawab semua pertanyaan dengan benar. Median skor post-test adalah 10 (Min-Maks =10). Data pada Gambar 2 menunjukkan pada tes awal para kader RW 4 sudah menjawab dengan benar pertanyaan nomor 9 dan 10. Para kader masih banyak menjawab salah pada pertanyaan nomor 1 sampai 8. Median skor pretest adalah 4,1 (Min-Maks = 5-10) Pada tes akhir para kader sudah bisa menjawab sebagian besar pertanyaan dengan benar. Median skor posttest adalah 7,3 (Min-Maks = 5-10). Hal ini menunjukkan sudah terjadi peningkatan pengetahuan kader dalam manajemen pengelolaan Posyandu Lansia.

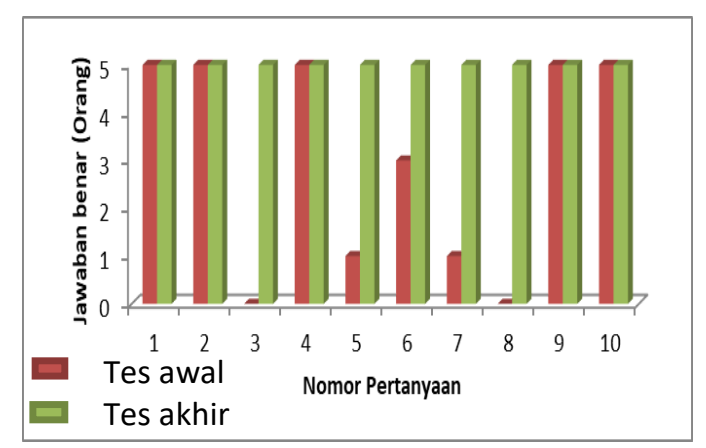

Gambar 1. Skor pre dan post tes kader RT1 dan 3 RW 1 dalam manajemen pengelolaan Posyandu Lansia 


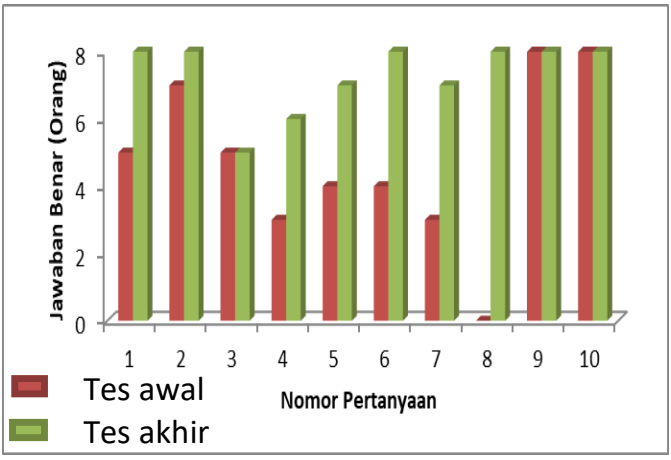

Gambar 2. Skor pre dan posttest kader RW dalam manajemen pengelolaan Posyandu Lansia

Posyandu lansia pertama, senam lansia, dan pendidikan kesehatan pola hidup sehat

Acara Posyandu Lansia pertama dan penyuluhan pola hidup sehat bagi Lansia diadakan pada tanggal 13 Mei 2017 di RT 1 dan 3 RW 1 dihadiri para lansia sebanyak 40 orang dan pada tanggal 20 Mei 2017 di RW 4 dihadiri sebanyak 44 orang. Setelah melaksanakan senam, para lansia istirahat sambil mendengarkan pendidikan kesehatan tentang pola hidup sehat yang diberikan oleh pengabdi dan petugas dari Puskesmas. Pengabdi dan kader kesehatan melakukan evaluasi bersama proses pelaksanaan Posyandu lansia yang pertama untuk perbaikan pada Posyandu Lansia selanjutnya. Profil peserta posyandu lansia ada pada Tabel 1 dan 2. Profil ini merupakan hasil kegiatan awal dalam pembentukan kader Posyandu Lansia, sebagai data peserta, sehingga dapat digunakan untuk monitoring kegiatan Posyandu Lansia.

Pada acara ini juga dilakukan evaluasi terkait pemeriksaan kesehatan yang dilakukan oleh para lansia sebelum dan sesudah adanya Posyandu Lansia. Evaluasi menggunakan kuisioner yang diisi oleh lansia. Hasil evaluasi pemeriksaan kesehatan disajikan pada Gambar 3 dan Gambar 4.
Tabel 1. Karakteristik Peserta Posyandu Lansia di RT 1 dan 3 RW 1 Kelurahan Bancarkembar Purwokerto Utara Kabupaten Banyumas

\begin{tabular}{lcc}
\hline Karakteristik & $\begin{array}{c}\text { Jumlah } \\
\text { (Orang) }\end{array}$ & $\begin{array}{c}\text { Persentase } \\
(\%)\end{array}$ \\
\hline Usia & & \\
\hline $45-59$ & 20 & 50 \\
\hline $60-70$ & 10 & 25 \\
\hline$>70$ & 10 & 25 \\
\hline Jenis Kelamin & & \\
\hline Laki-laki & 16 & 40 \\
\hline Perempuan & 24 & 60 \\
\hline Pendidikan & & \\
\hline SD & 22 & 55 \\
\hline SMP & 5 & 12,5 \\
\hline SMA & 11 & 27,5 \\
\hline $\begin{array}{l}\text { Sarjana, } \\
\text { master }\end{array}$ & 2 & 5 \\
\hline
\end{tabular}

Tabel 2. Karakteristik Peserta Posyandu Lansia di RW 4 Kelurahan Bancarkembar Purwokerto Utara Kabupaten Banyumas.

\begin{tabular}{lcc}
\hline Karakteristik & $\begin{array}{c}\text { Jumlah } \\
\text { (Orang) }\end{array}$ & $\begin{array}{c}\text { Persentase } \\
(\mathbf{\%})\end{array}$ \\
\hline Usia & & \\
\hline $45-59$ & 15 & 34 \\
\hline $60-70$ & 18 & 41 \\
\hline$>70$ & 11 & 25 \\
\hline Jenis Kelamin & & \\
\hline Laki-laki & 18 & 41 \\
\hline Perempuan & 26 & 59 \\
\hline Pendidikan & & \\
\hline SD & 31 & 70 \\
\hline SMP & 9 & 25 \\
\hline SMA & 2 & 5 \\
\hline
\end{tabular}

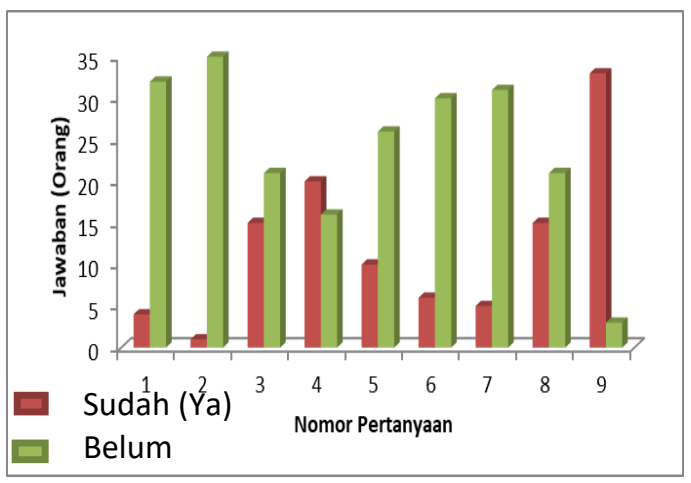

Gambar 3. Pemeriksaan kesehatan peserta sebelum dan sesudah dilaksanakan Posyandu lansia di RW 1 


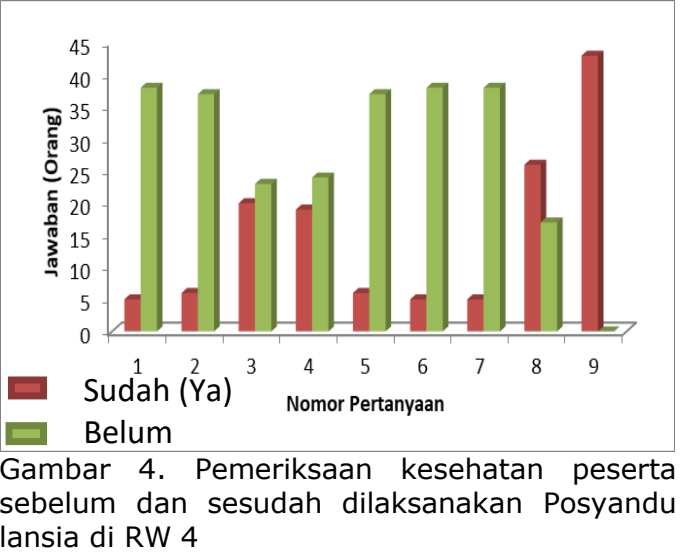

Data pada Gambar 3 menunjukkan bahwa warga RT 1 dan 3 RW1 Kelurahan Bancarkembar Kecamatan Purwokerto Utara Kabupaten Banyumas yang belum pernah mengikuti posyandu sebanyak $88 \%$ dan yang belum pernah mengikuti senam lansia sebanyak 97\%. Dalam tiga bulan terakhir, sebagian warga RT 1 dan 3 RW1 Kelurahan Bancarkembar sudah sebagian memeriksa tekanan darah dan berat badan namun banyak warga yang tidak memeriksakan kadar kolesterol, asam urat dan gula darah. Hampir semua warga RT1 dan 3 RW 1 membutuhkan adanya Posyandu Lansia (92\%).

Data pada Gambar 4 menunjukkan bahwa warga RW4 Kelurahan Bancarkembar Kecamatan Purwokerto Utara Kabupaten Banyumas yang belum pernah mengikuti posyandu sebanyak $88 \%$ dan warga yang belum pernah mengikuti senam lansia sebanyak $86 \%$. Dalam tiga bulan terakhir, sebagian dari warga RW4 Kelurahan Bancarkembar melakukan pemeriksaan tekanan darah dan berat badan namun banyak yang tidak pernah melakukan pemeriksaan kadar kolesterol, asam urat dan gula darah. Semua warga RW4 Kelurahan Bancarkembar menyatakan bahwa mereka membutuhkan adanya Posyandu Lansia.

\section{Posyandu lansia kedua dan siraman rohani}

Salah satu kebutuhan manusia adalah kebutuhan spiritual yaitu kebutuhan untuk lebih mendekatkan diri dengan sang pencipta, lebih banyak bersyukur kepada Allah, rajin sholat dan berzikir, berdoa serta mengikuti pengajian dan berinteraksi dengan orang-orang. Begitu juga dengan lansia, tentunya lebih banyak beribadah dan mendekatkan diri dengan Allah untuk bekal di akhirat. Menurut Tanaya dan Raka (2015) pada orang lanjut usia, mereka yang kurang religiusitas menunjukkan tingkat kepuasan hidup yang lebih rendah. Mereka yang religiusitasnya terbina dengan baik menunjukkan tingkat kepuasan hidup yang lebih tinggi. Berdasarkan hal ini maka perlu adanya siraman rohani untuk para lansia. Bertepatan dengan bulan Ramadhan, pengabdi menyelenggarakan acara siraman rohani untuk para lansia. Siraman rohani diadakan pada Tanggal 10 Juni 2017 di RT 1 dan 3 RW 1 dan tanggal 17 Juni 2017 di RW 4 yang diberikan oleh tokoh agama setempat. Posyandu tetap dilaksanakan dengan sistem 5 meja, selanjutnya lansia berkumpul di halaman rumah salah satu warga untuk mendapatkan siraman rohani. Selesai siraman rohani, lansia mendapatkan makanan tambahan berupa buah yang bisa dimakan pada saat berbuka puasa.

\section{Posyandu lansia dan pelatihan deteksi dini kadar kolesterol, asam urat, dan gula darah}

Pelaksanaan Posyandu Lansia ketiga dilaksanakan pada bulan Juli 2017. Posyandu dilaksanakan mulai pukul 7.30 sehingga belum terlalu panas dan lansia bisa senam terlebih dahulu. Pengabdi melakukan pelatihan cara melakukan pemeriksaan kadar kolesterol, asam urat dan gula darah bagi para kader Posyandu Lansia. Pelatihan tersebut diselenggarakan pada tanggal tanggal 9 Juli 2017 di RW 1 dan tanggal 16 Juli di RW 4 bertepatan dengan pelaksanaan Posyandu Lansia yang ketiga. Selanjutnya semua lansia diperiksa kadar kolesterol, asam urat dan gula darah oleh kader setelah kader Posyandu Lansia bisa melakukan 
sendiri pemeriksaan tersebut dengan didampingi oleh tim pengabdi. Berdasarkan hasil pemeriksaan kesehatan lansia diketahui bahwa masalah kesehatan utama pada lansia di Posyandu Lansia binaan adalah tekanan darah tinggi, kadar asam urat tinggi, dan kadar kolesterol yang tinggi. Tim pengabdi dan perawat dari Puskesmas memberi penyuluhan tentang manajemen nutrisi dan olah raga bagi lansia dengan masalah hipertensi, asam urat dan kolesterol. Bagi lansia yang membutuhkan tindakan lebih lanjut, memiliki keluhan, dan mengalami komplikasi disarankan untuk mendatangi Puskesmas Purwokerto Utara 1.

Tingginya kadar kolesterol dalam darah akan menyebabkan kerusakan sturktur pembuluh darah mulai dari penempelan lemak pada dinding pembuluh darah arteri kemudian dilanjutkan dengan kondisi menyempitnya lumen pembuluh darah. Kejadianselanjutnya adalah infiltrasi kalsium dalam lapisan otot polos tunika media arteri, hal ini memicu terjadinya proliferasi otot polos tunika media arteri, semakin banyaknya kalsium dan kolesterol dalam dinding akan mengurangi serabut elastis pembuluh darah. Kondisi ini menyebabkan perubahan struktur pembuluh darah dengan kondisi sempitnya lumen arteri, dinding yang rapuh dan tidak elastis yang disebut arterosklerosis, hal sperti ini tentulah terjadi secara lambat laun namun akibatnyasangatlah berbahaya bila tidak dilakukan usahausaha sejak awal untuk menurunkan kadar kolesterol darah, termasuk juga dengan mengontrol asupan makanan yang sehat (Harjana, 2011).

\section{KESIMPULAN}

Kegiatan PKM yang dilakukan menghasilkan Posyandu Lansia beserta kader yang terlaltih yang mampu mengkoordinasikan kegiatan Posyandu dan dapat melakukan pengecekan kesehatan dasar (tekanan darah, berat badan, tinggi badan, cek darah). Monitoring kegiatan PKM menunjukkan Posyandu Lansia secara rutin setiap bulan, dan senam lansia seminggu dua kali. Para kader Posyandu Lansia telah mengalami peningkatan pengetahuan dan keterampilan tentang manajemen Posyandu Lansia, kemampuan melakukan senam lansia, pengukuran tinggi badan, berat badan, tekanan darah, pemeriksaan kadar kolesterol, asam urat, dan gula darah. Selain itu, terjadi peningkatan pengetahuan lansia tentang senam lansia, pola hidup sehat, dan manajemen penyakit kronis. Lansia juga menyatakan bahwa saat ini mengetahui kondisi kesehatannya setelah dilakukan pemeriksaan kadar kolesterol, asam urat, dan gula darah. Pembentukan Posyandu Lansia di daerah lain diharapkan dapat dilakukan untuk mensukseskan program pemerintah melalui pemberdayaan masyarakat. Agar Posyandu Lansia yang telah terbentuk tetap berjalan dengan efektif maka pengabdi perlu melakukan beberapa rencana yaitu koordinasi dengan Puskesmas setempat agar mendapatkan pembinaan secara berkala dan melakukan pendampingan Posyandu Lansia pada masa awal pendiriannya.

\section{Ucapan Terimakasih}

Terima kasih kami ucapkan kepada Rektor Universitas Jenderal Soedirman, Ketua LPPM DP2M Universitas Jenderal Soedirman, Lurah Desa Bancarkembar, dan DP2M Dikti atas bantuan dana yang telah diberikan sehingga pengabdian kepada masyarakat ini dapat terlaksana dengan baik.

\section{DAFTAR PUSTAKA}

Bowling. A. 2007. Quality of life among older people with poor functioning. The influence of perceived control over life. Jurnal Kesehatan. Oxford University Press on behalf of the British Geriatrics Society. 
Camacho, G.B and Bixby, L.R, (2009). Differentials by Socioeconomic Status and Institutional Characteristics in Preventive Service Utilization by Older Persons, Journal Aging Health $21 ; 730$.

Dodo, D. 2009. Faktor- Faktor yang Berhubungan dengan Keaktifan Kader Dalam Pelaksanaan Kegiatan Posyandu di Kelurahan. Jurnal Pangan, Gizi dan Kesehatan. Tahun 1, Vol 1, No 1.

Federman, A.D, Pendrod, J.D, Livot, $E$, Hebert $P$, S, Doucette, J, and Siu, A.L, 2010. Development of and Recovery From Difficulty Wityh Activities of Daily Living : An Analysis of National Data. Journal Aging Health 22 ; 1081

Harjana, T., 2011. Kajian Tentang Potensi Bahan - Bahan Alami Untuk Menurunkan Kadar Kolesterol Darah. Prosiding Seminar Nasional Penelitian, Pendidikan dan Penerapan MIPA Fakultas MIPA, Universitas Negeri Yogyakarta.

Kementeriaan Kesehatan RI. 2014. Pusat Data dan informasi. Jakarta Selatan.

Pertiwi, H. W., 2013. Faktor-Faktor Yang Berhubungan Dengan
Frekuensi Kehadiran Lanjut Usia Di Posyandu Lansia. Jurnal IImiah Kebidanan, Vol. 4 No. 1

Sudaryanto, Agus, Irdawati. 2008. Persepsi lansia terhadap kegiatan pembinaan kesehatan lansia di posyandu wilayah kerja puskesmas Prambanan I Yokyakarta. Jurnal Kesehatan, ISSN 1979-7621, Vol 1. No. 1

Setyoadi, Ahsan, Abidin, A.Y., 2013. Hubungan peran kader kesehatan dengan tingkat kualitas hidup lanjut usia. Jurnal Ilmu Keperawatan, Vol 1. No.2 183-192.

Pemerintah Kabupaten Banyumas, 2016. UMK Banyumas Ditetapkan Rp 1.350.000. www.banyumaskab.go.id.

Rosyid (2008) Support to family carers of patients with frontotemporal dementia Health. Journal Aging \& Mental Health Vol. 12, No. 4, 462466.

Tanaya A. A R.R. dan I G. W. M. Yasa. 2015. Kesejahteraan Lansia Dan Beberapa Faktor Yang Mempengaruhi Di Desa Dangin Puri Kauh. PIRAMIDA Vol. XI No. $1: 8-12$.

UPT - Balai Informasi Teknologi LIPI. 2009. Gaya Hidup Sehat. Pangan \& Kesehatan. LIPI. 